\title{
Effect of Zonal Hydraulics on Energy Consumption and Boom Structure of a Micro-Excavator
}

\author{
Abinab Niraula ${ }^{1}(\mathbb{D})$, Shuzhong Zhang ${ }^{2}$ (i), Tatiana Minav ${ }^{1, *}$ and Matti Pietola ${ }^{1}$ \\ 1 Department of Mechanical Engineering, School of Engineering, Aalto University, 14400 Espoo, Finland; \\ abinab.niraula@aalto.fi (A.N.); matti.pietola@aalto.fi (M.P.) \\ 2 School of Mechanical and Automotive Engineering, Fujian University of Technology, Fuzhou 350118, China; \\ shuzhong_zhang@outlook.com \\ * Correspondence: tatiana.minav@aalto.fi; Tel.: +358-505-940-496
}

Received: 1 July 2018; Accepted: 7 August 2018; Published: 10 August 2018

check for updates

\begin{abstract}
This paper investigates the effect of extra weight caused by the Direct Driven Hydraulics $(\mathrm{DDH})$ in a micro-excavator. These projects are investigating the implementation of zonal or decentralized hydraulics for non-road mobile machinery (NRMM) and stationary industrial applications. The benefit of DDH is the combination of electric and hydraulic technologies in a compact package compared to conventional hydraulics, which enables a reduction of potential leakage points, flexible tubing, and boosting of the system efficiency due to switching to direct pump control instead of a loss-generating conventional valve-based control. In order to demonstrate these benefits for the excavator case, this paper proposes a system model approach to assess and predict energy consumption of the zonal hydraulics approach implemented with DDH in various working cycles, complemented by a structural analysis. The finite element analysis utilized for this demonstrated that the extra weight and selected location of DDH units do not negatively affect the structure of the excavator. Simulation results demonstrated that the energy consumption is approximately $15 \%$ higher with extra weight added by the three DDH units. Although approximately $20 \%$ more regeneration energy is produced, taking into account the regeneration energy, the increases in energy consumption are about $12 \%$.
\end{abstract}

Keywords: hydraulic excavator; hydraulic drives; electric drives; efficiency; losses; zonal hydraulics; direct driven hydraulics; off-road mobile machinery; energy consumption; finite element analysis

\section{Introduction}

Hybrid and electric systems for vehicles are required by regulations of the European Union (EU) [1] and the United States (USA) [2], among others. As a response to this, an increasing amount of proposals for ecological and greener technological solutions are arising from academic and industrial environments. One of the potential industries for the application of greener solutions is non-road mobile machinery (NRMM). These are widely utilized in mining, goods manufacturing, forest harvesting, cargo logistics, construction, and agriculture. An excavator is an example of construction machinery with its own challenges, such as various working cycles, a variety of end tools, and the size of the machine in general. Academic studies related to excavators mostly concentrate on electrification and hybridization on swing and boom motion to recover the kinetic and potential energy [3-5]. For instance, [6] proposed a hybrid drive in a 20-tonne excavator. In [7], displacement-controlled architecture was applied to a 5-tonne excavator to capture the braking energy of the cabin swing motion. In [8], the standard drive system was compared with the energy recuperation drive system and demonstrated $10 \%$ energy saving in one cycle. However, the construction machinery and off-road industry is facing challenges on energy saving due to the high output power required on its 
duty cycle and fuel consumption. The NRMM market has also responded quickly to electrification trends with new products. For instance, companies in [9-12] introduced partially electrified to fully electric excavators.

However, most of these academic studies and market examples concentrate on replacing the conventional power source with electric ones and developing a powertrain with unchanged conventional working hydraulics. To overcome this narrow scope, a zonal or decentralized hydraulic network could open up new approaches for more electric hybrid and electric powertrains. Previous studies on the implementation of the zonal hydraulics already demonstrated improvements in NRMM [13,14] and in stationary industrial applications [15]. The zonal hydraulics can be implemented with pump-controlled units, such as Direct Driven Hydraulics (DDH), where flow delivered to the actuator is controlled directly by the speed of an electric motor instead of valves. For instance, in [16] the authors demonstrated the advantage of utilizing DDH in a micro-excavator by means of modelling. The improvement in excavator system efficiency was demonstrated to increase from $20 \%$ with conventional low-cost load-sensing (LS) systems to $71 \%$ with DDH. However, the weight and location of the DDH units were not considered in the earlier studies. Therefore, in this study these effects of the DDH unit is investigated from a structural and energy consumption and efficiency point of view.

This study proposes that the DDH units are attached to the arm and boom on the front hoe of the micro-excavator. These locations are selected due to the presence of attachment holes in the front hoe. The weight of the three attached DDH units is comparable to the weight of the boom and arm itself. In order to assure safety with the additional weight introduced by attaching DDH units on the front hoe, the changes in the mechanical behaviour of the front hoe parts should be studied. The structural analysis of extra load-bearing parts (for instance the boom, arm, and kingpost) provide an approximate prediction of the stress conditions and deflections after attachment of DDH units on a micro-excavator. The micro-excavator is a complex machine with multiple moving parts and connections. The bucket load does not act directly on cylinders and other structural elements: but it is divided and transferred to each component on the load path from the bucket to the kingpost and beyond. The parts and mechanism of the front hoe, i.e. parts and mechanisms from kingpost to bucket, are studied in this paper.

This paper proposes a system-model approach to assess and predict the overall energy consumption of the DDH drive in various working cycles in a micro-excavator case. A 3D model of the micro-excavator is created using PTC CREO 3.0 (Parametric Technology Corporation, Needham, MA, USA) to study the mechanisms and perform multibody simulations. The developed model is utilized in dynamic analyses, with extracted payloads for structural analysis using the finite element method built into CREO 3 .

The test case excavator with zonal hydraulics is introduced in Section 2, while Section 3 introduces the methods and results of the structural analysis. The description of the proposed electro-hydraulic model for this study case and the simulation results and their analysis for energy efficiency are presented in Section 4 . Thereafter, Sections 5 and 6 contain a discussion and concluding remarks.

\section{Test Case}

A 1-tonne class J.C. Bamford Excavators Limited (JCB) micro-excavator is utilized as a test case (Figure 1. The DDH consists of one electric drive (electric motor controlled by a variable frequency converter) and two bi-directional hydraulic motors (working as pump/motors) coupled on one shaft. In addition, the tank of the DDH was substituted with a low-pressure hydraulic accumulator. When the cylinder extends and retracts, the hydraulic accumulator discharges and charges fluid, respectively, to balance the flow of the cylinder. The speed of the electric motor and displacement of hydraulic pump/motors defined the flow to the double-acting differential cylinder. 


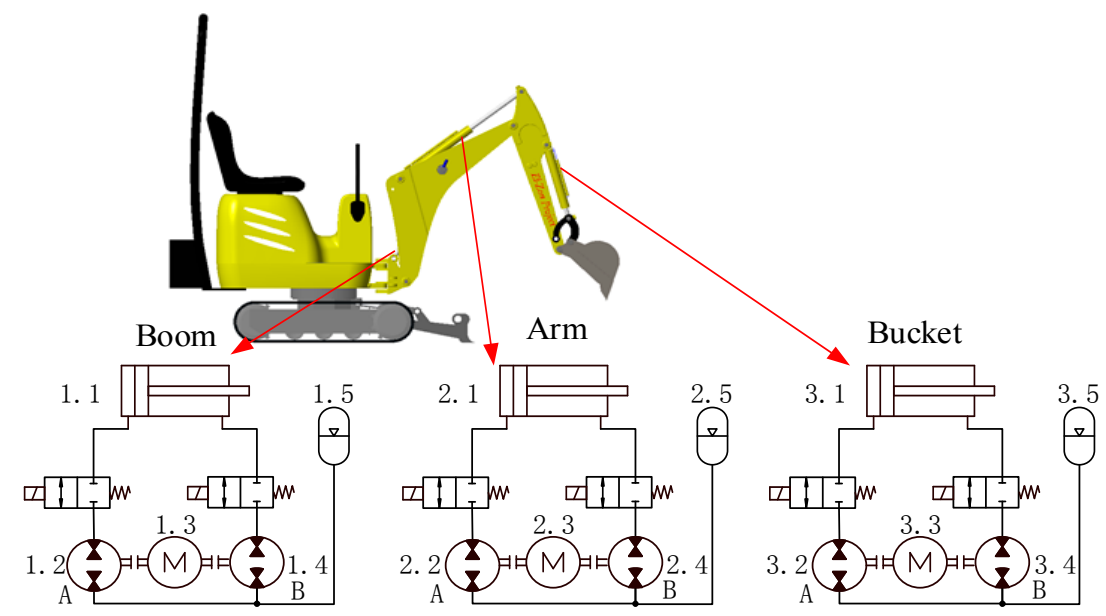

Figure 1. Schematics of the utilized test case: J.C. Bamford Excavators Limited (JCB) micro-excavator.

Therefore, the velocity of the cylinder can be adjusted via the electric motor's speed control. In addition, the pump/motor can be run in motoring mode when the potential and braking energy sends feedback from the front hoe of the excavator. In this case, the electric motor works as a generator, and the energy will be converted back into electric power. The methodology introduced in [17] is scaled up for the test case of the micro-excavator. Table 1 contains information about pre-chosen components.

Table 1. Information about selected components.

\begin{tabular}{|c|c|c|c|}
\hline Component & Figure 1 & Description and Dimensions & Mass (kg) \\
\hline Boom cylinder & 1.1 & $60 / 30 \times 325 \mathrm{~mm}$ & 16.0 \\
\hline Pump/Motor & $1.2,1.4$ & $\begin{array}{l}\text { External bi-directional gear motors by } \\
\text { Hydac with displacements of } 6.61 \text { and } \\
\qquad 4.95 \mathrm{~cm}^{3} / \mathrm{rev}[18] .\end{array}$ & 6.6 \\
\hline Electric motor & 1.3 & MST130C-0200-F, 5.24 kW [19] & 6.6 \\
\hline Hydraulic accumulator & 1.5 & 0.7L@1bar by Bosch Rexroth & 4.0 \\
\hline Arm cylinder & 2.1 & $50 / 30 \times 410 \mathrm{~mm}$ & 11.0 \\
\hline Pump/Motor & $2.2,2.4$ & $\begin{array}{l}\text { External bi-directional gear motors by } \\
\text { Hydac with displacements of } 6.67 \text { and } \\
\qquad 4.27 \mathrm{~cm}^{3} / \mathrm{rev}[18] .\end{array}$ & 2.4 \\
\hline Electric motor & 2.3 & MST130C-0200-F, 5.24 kW [19] & 6.6 \\
\hline Hydraulic accumulator & 2.5 & 0.7L@1bar by Bosch Rexroth & 4.0 \\
\hline Bucket cylinder & 3.1 & $50 / 30 \times 292 \mathrm{~mm}$ & 9.0 \\
\hline Pump/Motor & $3.2,3.4$ & $\begin{array}{l}\text { External bi-directional gear motors by } \\
\text { Hydac with displacements of } 6.67 \text { and } \\
\qquad 4.27 \mathrm{~cm}^{3} / \mathrm{rev}[18] .\end{array}$ & 2.4 \\
\hline Electric motor & 3.3 & MST130C-0200-F, 5.24 kW [19] & 6.6 \\
\hline Hydraulic accumulator & 3.5 & 0.7L@1bar by Bosch Rexroth & 4.0 \\
\hline
\end{tabular}

A multibody model was created with the measured weight and dimensions of the existing micro-excavator by disassembling it, and the cycles were simulated in CREO 3.0. The mass of each DDH unit was estimated to be $29 \mathrm{~kg}$. The weight of each DDH unit is calculated by summing up the weight of its components, which includes two pump/motors, one accumulator, one electric motor, pipes, and the structure for attaching. The weight of an individual component is extracted from its 
datasheet. The mass distribution of the front hoe is presented in Table 2, which reveals that the mass of the DDH units are comparable to the mass of the boom, arm, and bucket.

Table 2. Mass distribution on the front hoe of the micro-excavator with Direct Driven Hydraulics (DDH) units.

\begin{tabular}{cccc}
\hline Component & Structure (kg) & Cylinder (kg) & DDH Units (kg) \\
\hline Boom & 59.5 & 16.0 & 29.0 \\
Arm & 28.0 & 11.0 & 29.0 \\
Bucket (including linkage) & 40.0 & 9.0 & 29.0 \\
\hline
\end{tabular}

Each connection in the structure experiences load reactions due to the cycles used. The load reactions in these cycles were extracted from CREO after each cycle, and the cycle with the maximum reaction load on the joints of the micro-excavator was determined. These load values were defined as input loads for finite element analysis (FEA) in the inbuilt finite element analysis module of CREO 3.0.

\subsection{Cycles}

In order to evaluate the effect of DDH on the mechanical properties and efficiency of an excavator, it is necessary to define the actual operation of such a machine. Typically, the real cycles are composed of many small cycles, which can be obtained from the literature. However, the varying loading conditions and sizes make standardizing a difficult task, as the excavators are operated under various conditions. Therefore, in this study the following cycles were adopted in order to acquire a comparable analysis.

Specific test cycles were required to determine the maximum forces on the excavator parts. No specified test cycles and loading conditions were standardized that could be implemented to determine the maximum forces on the front hoe parts of the micro-excavator. Therefore, during the research, several cycles were designed to mimic the working nature of a micro-excavator with the expectations to define the highest loads on each cylinder and the kingpost-boom joint. Due to the limited availability of standard cycle definitions, the Japan Construction Mechanization Association (JCMAS) duty cycles were followed in digging and leveling cycles, although, a micro-excavator was employed in the research. The JCMAS cycles are designed for larger excavators and are executed without the load. Implementing them directly did not push the system to its limits, and therefore some modifications were implemented by applying the load on the bucket. The loading on the bucket also depends on the velocity of the bucket, which in turn depends on the cycle time. During the study of a typical performance cycle of mobile machinery-while taking the operator influence into account-it was established that the level of expertise of the operator has a crucial effect on cycle times. It was concluded that the experienced operators are likely to have a shorter cycle time for the same task compared to less experienced ones, according to [20]. In [20], the authors concluded that an experienced operator had an average cycle time of 24.5 seconds, while inexperienced ones had about 47 seconds to perform a similar trenching cycle with a 20-tonne capacity excavator. The cycle time of 20 seconds has been utilized for the micro-excavator in this paper.

\subsection{Extreme Cycle}

A special cycle was designed to evaluate the extreme loads in the operation of the micro-excavator. The extreme cycle is demonstrated in Figure 2. The highest boom-cylinder load is acquired in a cycle where the boom cylinder is driven from its minimum length to its maximum length while keeping the arm cylinder at the minimum length and the bucket cylinder at a constant length to keep the bucket farthest from the boom-kingpost joint. 

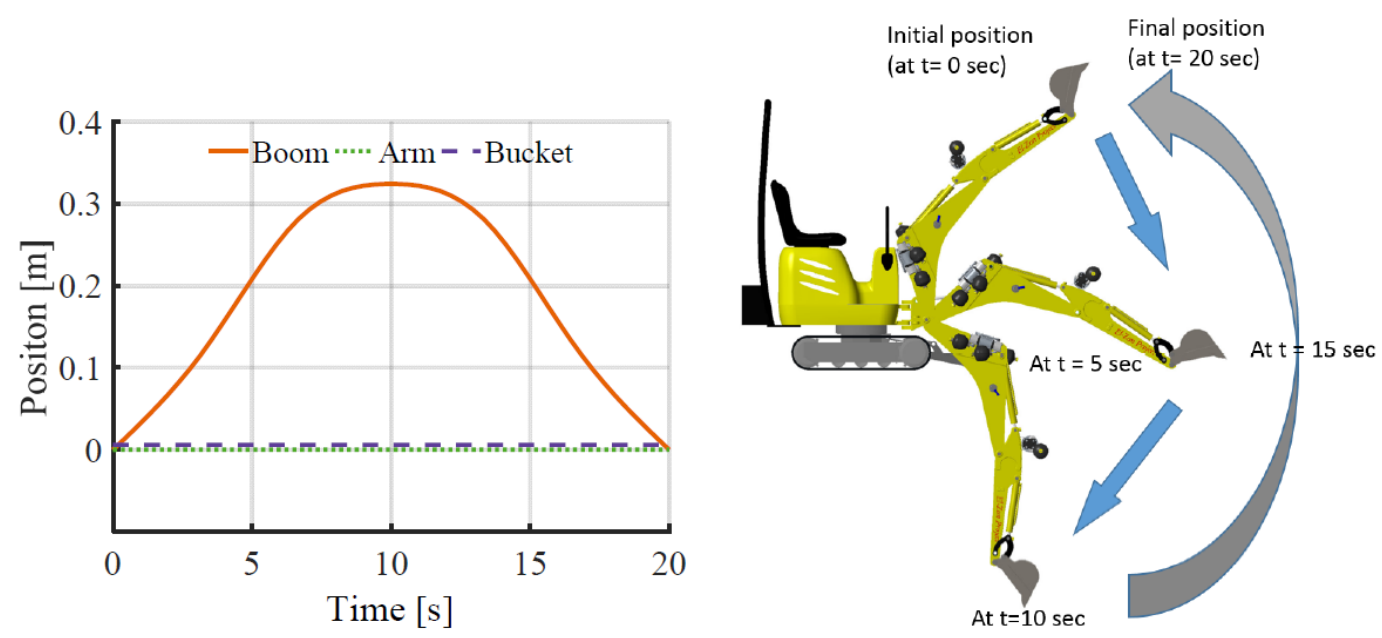

Figure 2. Utilized extreme working cycle with the demonstration of the excavator position.

\subsection{Typical Working Cycle}

An example of a typical working cycle for the excavator from [21] was adopted as the input reference for this investigation. The positions of the excavator cylinders and their operating sequence are illustrated in Figure 3. From here, this cycle will be referred to as a typical working cycle. The load conditions for this cycle are explained below in subsection titled Load.

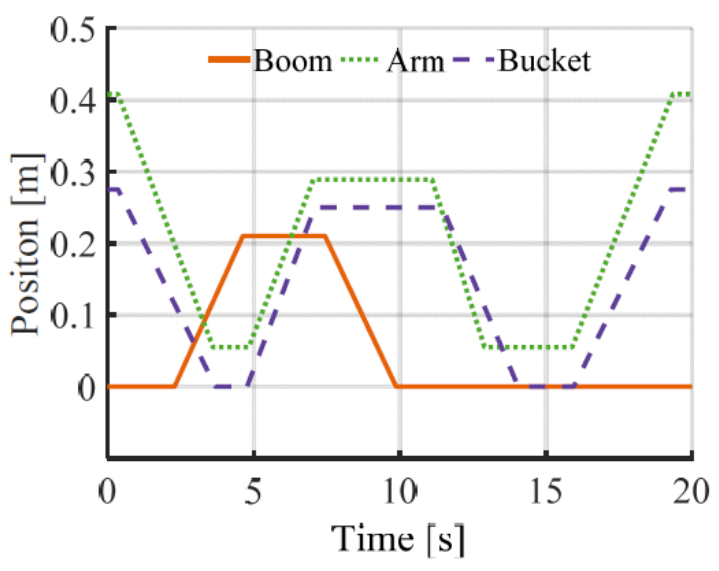

Figure 3. Typical working cycle.

\subsection{Modified Japanese Cycle}

The JCMAS duty cycles, standardized to test the fuel consumption of hydraulic excavators [22], was adopted as a reference in this study. The cycles are scaled down to suit the micro-excavator adopted in this project, as it is smaller than required according to the standard. The swing motion is omitted, and only the cylinder movements of the front hoe are utilized in the scope of this work. Further details about adapting the cycle are explained in [23]. The reference cylinder lengths for each cylinder are compared with the visualization of the utilized cycle, illustrated in Figure 4 for the digging and levelling cycle, respectively.

The digging load during an excavation is not constant. It increases rapidly while digging, stays constant until the load is dumped, and decreases rapidly while the load is dumped. Determining the digging load is a complicated process in itself, and it is not necessarily similar in different cycles of the same nature. Using such a load, which is at maximum only during a certain time span, would not produce the largest reactions to determine the worst loading case of the micro-excavator. Therefore, 
a constant load of the highest load value for the bucket was embraced. The load definitions are explained in the following subsection.

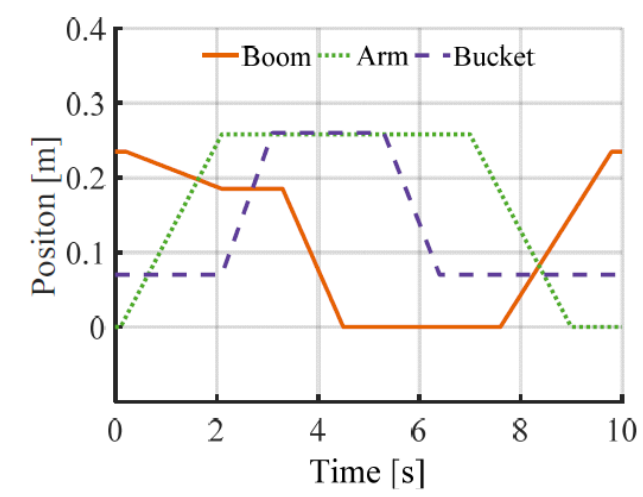

(a)

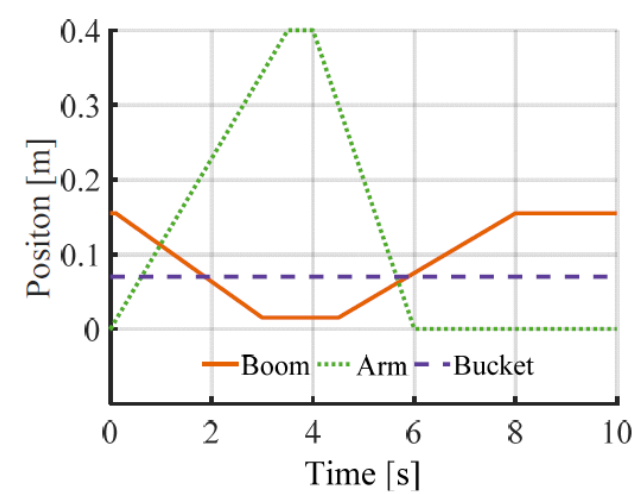

(b)

Figure 4. Modified Japanese cycle (a) digging; (b) levelling.

\subsection{Payload}

In this study, the load definition was based on the weight of the total volume of sand that the bucket can carry. The bucket of the micro-excavator has a $24 \mathrm{~L}$ capacity when it is not heaped. The volume of soil it can carry increases when heaping on the top of the bucket is considered. The standard methods to estimate such loads, for instance the Society of Automotive Engineers (SAE) SAE J2754-2007 and the British Standard (BS) BS 6422:1983 define the outline of loading the bucket in heaped conditions. The SAE (1:1) [24] and Committee of European Construction Equipment (CECE) (2:1) standards [25] define the angle of the heap in two dimensions, as shown in Figure 5.

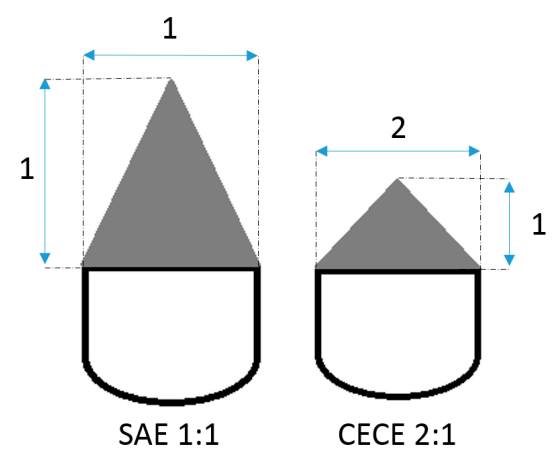

Figure 5. Heaping according to Society of Automotive Engineers (SAE) and Committee of European Construction Equipment (CECE) standards [26].

The volume of the bucket was calculated with dimensional measurements and corresponds to 34.2 L. These dimensions were used to model it in CREO 3.0. An empty bucket was modelled and filled with material, first without and then with heaped material, as shown in the figure below. In order to determine the loads on the bucket, material was modelled to fill the bucket volume following the interior shape of the bucket. The density of the material was defined as $2100 \mathrm{~kg} / \mathrm{m}^{3}$ (selected density value is between soil and rock). The CECE (2:1) standard was selected because if SAE is adopted, the arm would obstruct the top of the bucket due to the limited free space in the geometrical arrangement of the bucket under the arm. Therefore, the maximum bucket load is defined based on the heaped material volume it can carry with respect to CECE 2:1 standard, as demonstrated in Figure 6. 


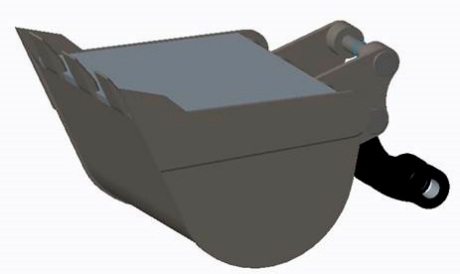

(a)

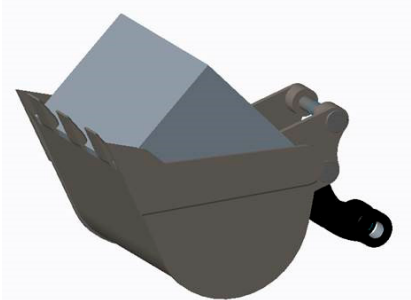

(b)

Figure 6. Bucket full of load: (a) full; (b) heaped according to CECE 2:1.

The gravitational force acting on the soil filled in the bucket is calculated. It is referred to as the peak load of the bucket during excavation. The peak bucket load is calculated and corresponds to $705.549 \mathrm{~N}$. The load due to the soil-filled bucket can be calculated with the volume of the bucket and density of the soil. The densities [27] of some commonly excavated materials are tabulated, and the respective masses as well as the resulting weight of the load are calculated and tabulated in Table 3.

Table 3. Maximum bucket load during the excavation of different materials [27].

\begin{tabular}{cccc}
\hline Material & Density $\left(\mathbf{k g} / \mathbf{m}^{\mathbf{3}}\right)$ & Maximum Mass * $\mathbf{( k g )}$ & Weight $(\mathbf{N})$ \\
\hline Clay (Low plasticity index) & 1650 & 56.529 & 554.36 \\
Clay and gravel & 2100 & 71.946 & 705.549 \\
Sand & 2000 & 68.52 & 671.952 \\
Sand and gravel & 1950 & 66.807 & 655.153 \\
Sandstone (porous) & 2500 & 85.65 & 839.94 \\
Sandstone (cemented) & 2650 & 90.789 & 890.336 \\
Limestone & 2600 & 89.076 & 873.537 \\
\hline
\end{tabular}

* Maximum mass that can be fitted in the bucket volume.

Most of these values express the load when the pure material was filled; but in daily use, the excavated rubble is mixed with soil and other elements as well as air in-between the particles. The loose nature of rubble greatly reduces the density of the material to be excavated. In the daily use of a micro-excavator, the most common materials that undergo excavation are sand or clay mixed with gravel. Therefore, the density of clay and gravel, $2100 \mathrm{~kg} / \mathrm{m}^{3}$, has been utilized in this paper. Hence, the maximum bucket load of $71.946 \mathrm{~kg}$ or $705.549 \mathrm{~N}$, which always acts vertically downward along the direction of gravity, has been adopted in this study.

During the excavation process, there are other forces in action introduced due to bucket-soil interaction. It can be reasonably assumed that the time span of the soil-bucket interaction during soil digging or shearing and loading of soil in the bucket is small compared to the whole cycle time of the excavation operation. These additional loads that appear for a short interval of time are more complicated to evaluate, as they introduce multiple non-linearities during the short span of the bucket-soil interaction. Apart from that, this paper only discusses the effects due to the addition of the $\mathrm{DDH}$ units on the front hoe of the micro-excavator; therefore, these additional short-lived loads are omitted in this paper. The frictional forces within the cylinders and the joints are considered negligible in comparison to other loads, so they are neglected in this study.

\subsection{Digging Load Profile}

The digging load has a characteristic profile described by [21] which captures the increasing profile of the load while digging, its constant nature while the bucket is holding it, and the decreasing of the load while it is being emptied. This nature of the external load was utilized to mimic the everyday operation of the micro-excavator in this paper. The highest value of the load that momentarily stays 
constant in the bucket has been equated to the weight of the rubble/load on the bucket when it is heaped. The modified load definition with the maximum load of $705.549 \mathrm{~N}$ is presented in Figure 7.

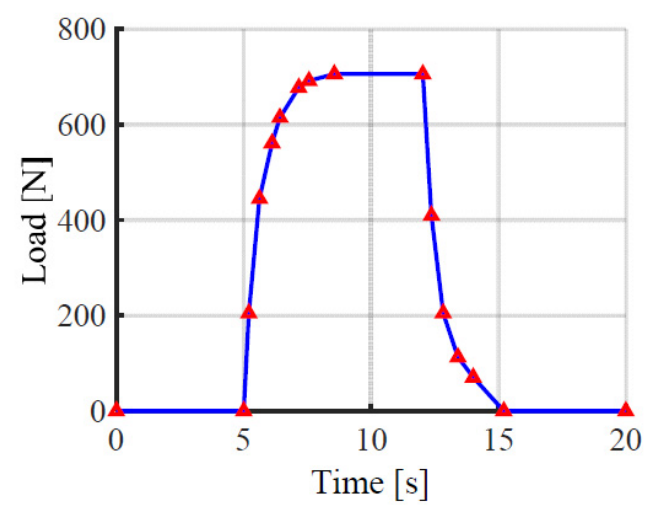

Figure 7. Digging load force profile versus time.

The time of loading has been adjusted to the digging cycle. The simplified load is illustrated in Figure 7. Since it is difficult to determine the terra-mechanical forces on the bucket during an actual digging cycle, a simplified simulated time-dependent load of the moving load was implemented [21]. Respective to this, the $y$-axis in Figure 7 corresponds to the load magnitude in $\mathrm{N}$.

The following section introduces the mechanical analysis of the micro-excavator utilizing the cycles and the load presented above.

\section{Mechanical Analysis}

A 3D model of the micro-excavator was created using CREO 3.0, shown in Figure 8. It was created to study the mechanisms and perform multibody simulations. The dynamic analyses were conducted to extract the necessary peak loads for the structural analysis. The structural analyses were executed using the finite element method in the inbuilt finite element analysis module of CREO 3.0.

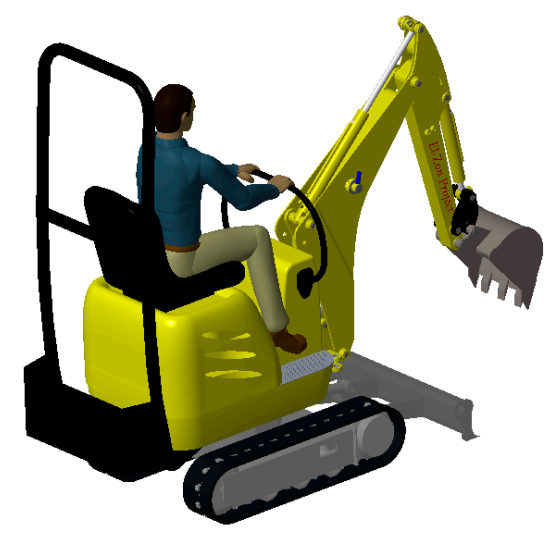

Figure 8. 3D model of the micro-excavator with a mannequin to approximate the size of the excavator.

\subsection{Determining the Critical Components for the Structural Analysis}

Different loading cycles were utilized to check the cylinder loads while applying the same load profile, as specified above in Figure 7. The utilized operational cycle was defined in Figure 3. It was simulated in CREO 3.0, and the reaction forces on the three cylinders were measured. The reactions on the three hydraulic cylinders are presented in Figure 9: the left graph represents the reactions with the DDH units, and the right graph without the DDH units. From Figure 9a,b, it can be observed that the addition of the DDH units on these locations has a significant impact on the reaction load of the boom 
cylinder. A maximum load of $20.736 \mathrm{kN}$ was obtained from the boom cylinder with the DDH units attached, while without the DDH units the maximum load was $16.436 \mathrm{kN}$.

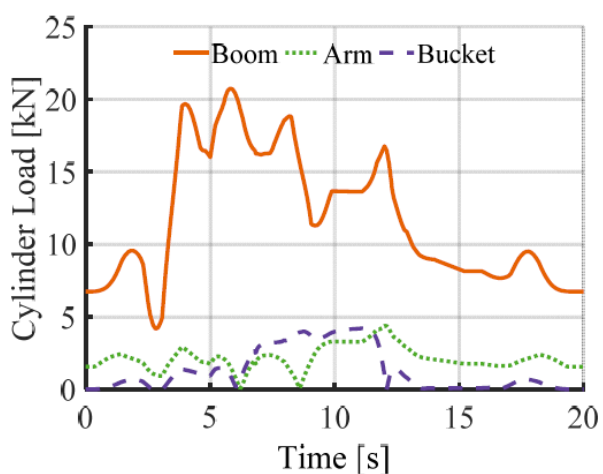

(a)

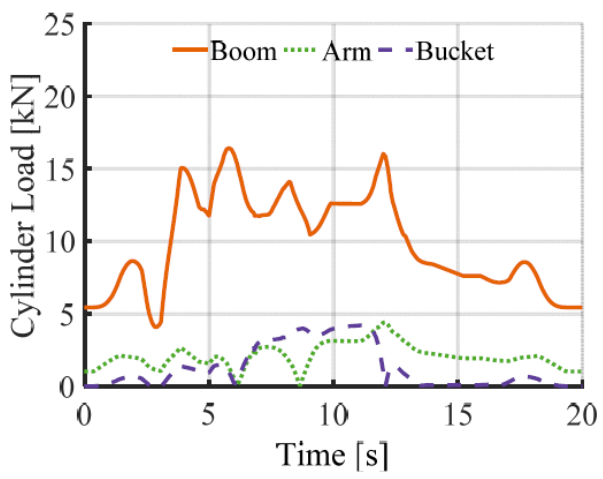

(b)

Figure 9. Cylinder reactions from the operational cycle with the $71.946 \mathrm{~kg}$ load: (a) with the DDH units; (b) without the DDH units.

The arm cylinder did not demonstrate significant changes despite the load due to the geometry and distances of added mass from its support joints. After observing this behaviour, the boom, boom cylinder, and the kingpost on the front hoe were deemed critical components for further analysis.

\subsection{Structural Analysis}

The boom is connected to the kingpost, arm, bucket cylinder, and the boom cylinder. The maximum loads on the boom joints are difficult to define, as they depend on many parameters, such as the weight of each component, bucket load, speed of the cylinders, and position of the cylinder. Since there are many possible cycles, it is difficult to specify the exact extreme case for the excavator. The dynamic analysis of the above-defined operational cycle results in a maximum load for the boom cylinder in that cycle, but the reaction load changes if the cycle is changed. The cycle that produces the highest load on the boom cylinder would be the extreme case cycle for the boom and kingpost. Several test cycles were designed and analysed to determine the extreme case cycle for the boom and kingpost. The cycle definition of the utilized extreme case cycle is presented in Figure 2.

The boom cylinder reaction forces for the extreme case and operational cycle with DDH units and the payload of $71.946 \mathrm{~kg}$ is demonstrated in Figure 10a,b, respectively. The boom load measured from this cycle are almost twice that of the operational cycle.

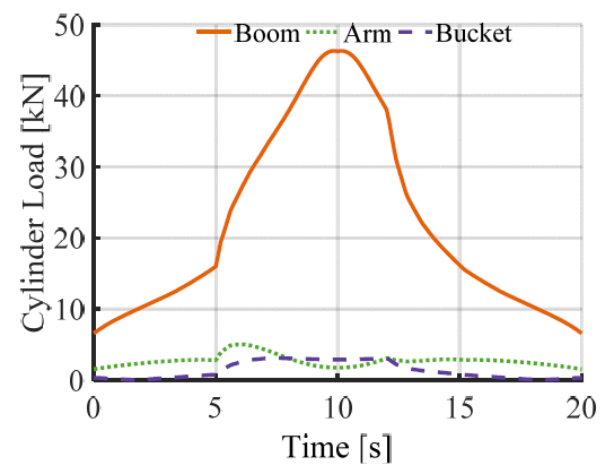

(a)

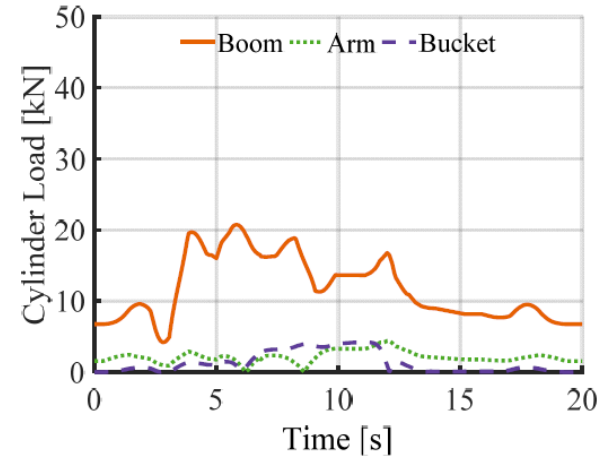

(b)

Figure 10. Boom cylinder reactions with DDH units and load of $71.946 \mathrm{~kg}$ : (a) extreme case cycle; (b) operational cycle $(\mathrm{Max}=46.280 \mathrm{kN})$. 
The load definition here follows the trend of a normal digging cycle. Such a bucket load has a maximum load only for a short interval and then disappears after some time, as described in the load cycle above. A load definition of this nature would not capture the highest possible reaction force on the boom cylinder during the initial and final phases of the cycle. Therefore, a constant load is applied throughout the cycle acting vertically down with a maximum magnitude of $71.946 \mathrm{~kg}$. It would represent a hypothetical case where a heaped load of clay and gravel would be fixed in the bucket. The highest cylinder load magnitude in $\mathrm{N}$ during the extreme case cycle with the constant load of $71.946 \mathrm{~kg}$ is illustrated in Figure 11. Such a load case may not be applicable during the common application of an excavator. However, it has been utilized to represent the maximum load magnitude that could occur in the daily operation of this excavator and to extract the highest reaction loads on the joints of boom and kingpost for structural analyses.

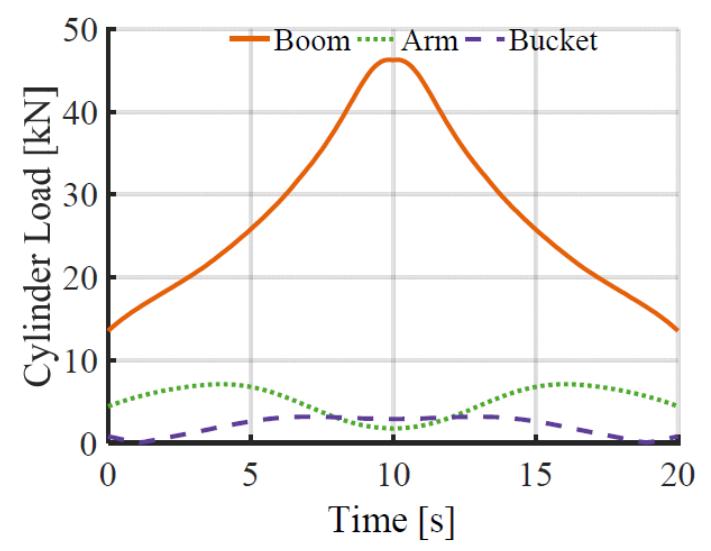

Figure 11. Highest cylinder load magnitude in $\mathrm{N}$ during the extreme case cycle.

With the new load definition of a constant $71.946 \mathrm{~kg}$ load throughout the cycle, the peak load on the boom cylinder remained relatively constant, and a slight increase in the arm and bucket cylinder load is noticeable. The cycle resulting in the highest loads on the boom was employed to extract the required input loads for finite element analysis.

\subsection{Finite Element Analysis (FEA)}

The structural analyses of the parts were carried out with the Finite Element Method. The boom was determined to be the most critical part, and a structural analysis was performed. Among the parts, the kingpost and boom are connected with a pin connection. They have a similar loading across the joint, but despite the similar loading, the kingpost is heavily built compared to the boom. The wall thickness and bushing around the connection holes on the kingpost are much thicker compared to that of the boom; therefore, the analysis of kingpost is not considered critical. The hydraulic cylinder is protected by a pressure relief valve which prevents it from overloading. Hence, its structural analysis is omitted. The FEA analysis was executed with certain assumptions about the material involved. The material is assumed to be homogeneous, and the general mechanical property of steel as registered in the inbuilt material library of CREO 3.0 was used, as mentioned in Table 4.

Table 4. Material properties implemented in the structural analyses.

\begin{tabular}{cc}
\hline Material Properties for Steel & Magnitude \\
\hline Density & $7827.08 \mathrm{~kg} / \mathrm{m}^{3}$ \\
Poisson's ratio & 0.27 \\
Young's Modulus & $199.948 \mathrm{GPa}$ \\
\hline
\end{tabular}


The boom has four pin joints with holes on the boom and shafts connecting it to other components. A pin connection restricts the translation of the component along both the horizontal and vertical axes but allows free rotation along one axis. In other words, it can provide support to translational forces but does not provide any moment reaction against the applied load. This simplified connection produces only radial forces on the joints, reducing the complexity of the structural analysis.

The joint reactions with this load case were measured on all joints of the boom, and the result was utilized as the input load for the structural analysis in the inbuilt finite element module of CREO 3.0. The structural analysis in this study was performed to investigate the stress and deformation of the boom. The free body diagram for the boom being analyzed is presented in Figure 12. The loads applied to the boom and its fixed end are labelled in the free body diagram. In order to simulate the extreme case, the boom cylinder was extended to its maximum length, and the highest bucket load defined above was applied on the bucket. The load values along with their directions are directly imported to the simulation environment of CREO 3.0 from the mechanism analysis of CREO.

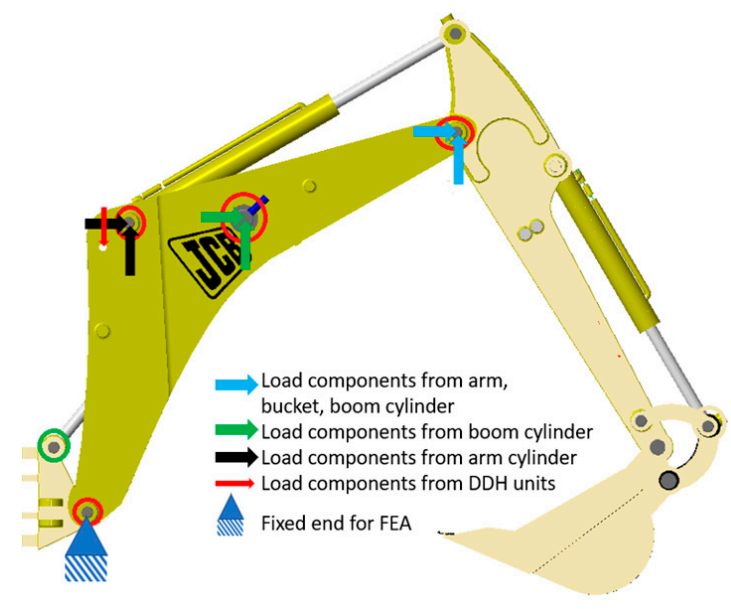

Figure 12. Free body diagram.

The FEA simulation was performed on the 3D model of the boom using solid elements. The boom was constrained using the displacement constraint setting where translation and rotation along all three axes were fixed. The constraint was applied to the boom-kingpost joint, which is the main support joint for the front hoe. With all the applied constraints and loads, the FEA was performed. Below, Figure 13 demonstrates stresses in MPa on the boom due to the highest loads during the extreme case cycle with DDH units and without DDH units. The stresses in the boom with and without DDH units are compared with exactly the same load and boundary conditions. The FEA analysis result demonstrated that the highest stress was near the boom-boom cylinder joint in both cases. The highest stresses observed in the boom were 144.34 MPa with DDH units and 107.58 MPa without DDH units, as shown in Figure 13. The resulting displacement of the boom due to the highest loads from the extreme case cycle with DDH units and without DDH units are demonstrated in Figure 14a,b, respectively. The maximum deflection with the same load and constraint was $1.708 \mathrm{~mm}$ with DDH units attached and $1.500 \mathrm{~mm}$ without the DDH units. The load values utilized in this analysis are the highest loads that the current micro-excavator might face if operated for actual field applications. Such a load with the equivalent weight of a heaped bucket would not be driven to the lowest reach of the excavator during its operation. Even so, the stress values observed were not alarmingly high for the steel in general. Therefore, these increases in stresses and deflections are considered safe in order to make the necessary modifications and attach the DDH units for further research. 


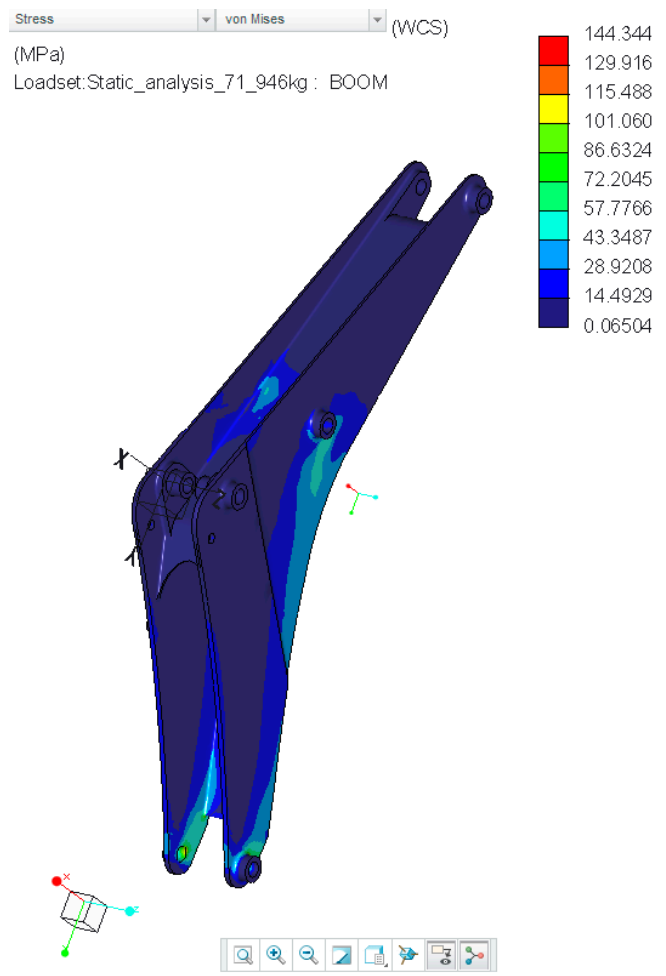

(a)

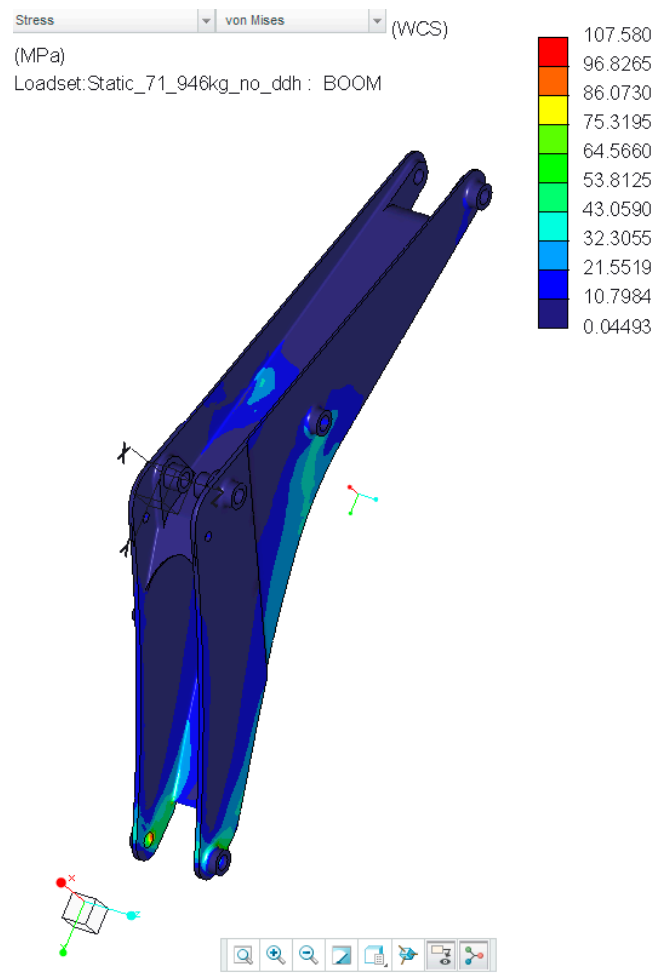

(b)

Figure 13. Stresses (MPa) on boom due to the highest loads from the extreme case cycle (a) with DDH units; (b) without DDH units.

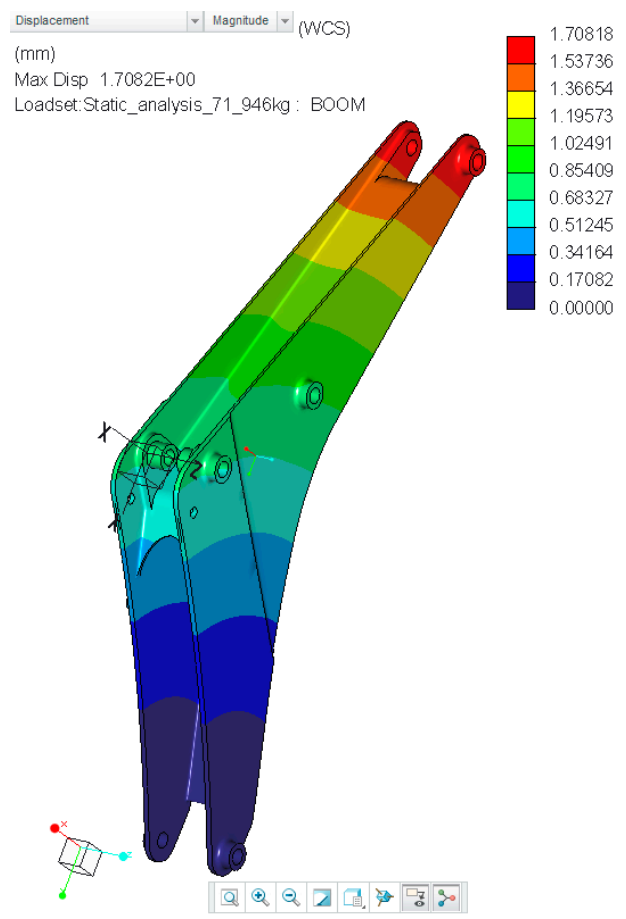

(a)

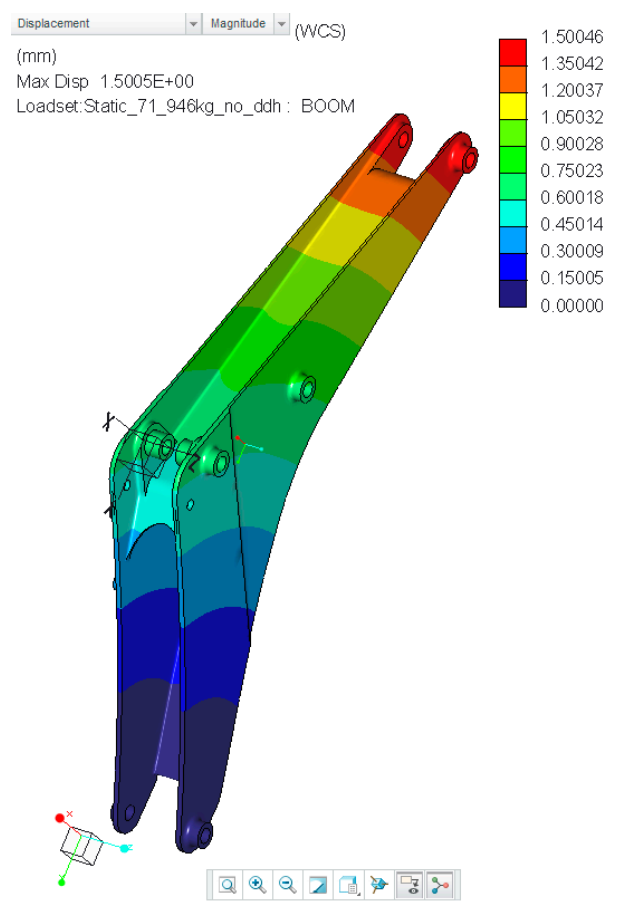

(b)

Figure 14. Displacement $(\mathrm{mm})$ of boom due to the highest loads from the extreme case cycle (a) with DDH units; (b) without DDH units. 
The purpose of the FEA in the boom was to assure the absence of dramatic changes in stresses due to the addition of DDH units. The attachment of two DDH units on the boom adds $58 \mathrm{~kg}$ of weight on the boom itself. The DDH units are attached to the hooking holes of the boom designed to lift the boom in case of disassembly or transportation. It is observed that the additional weight does not cause significant changes in the local stresses of the boom at the attachment region. With these observations, it can be concluded that the addition of the DDH units on the front hoe does not have a detrimental effect on the structural capabilities of the micro-excavator.

\section{Energy Consumption and Efficiency Analysis}

The following sub-sections contain simulation results for the electro-hydraulic modelling and results.

\subsection{Modelling}

The model of the excavator consists of the mechanical model (with or without DDH units) coupled with electro-hydraulics models. The 3D solid mechanical model of the excavator was constructed in Creo 3.0. The weight of the excavator part was measured, and material was assigned to each part in the Creo program to match the measured weight. The 3D model of each DDH unit was built and weight of DDH unit is estimated to be $29 \mathrm{~kg}$. The multibody dynamic model with and without DDH units was exported from Creo and imported into MATLAB (R2016b, MathWorks, Natick, MA, USA) Simscape using the Simscape Multibody Link Plug-In. Figure 15 presents the mechanical model with and without the DDH units.

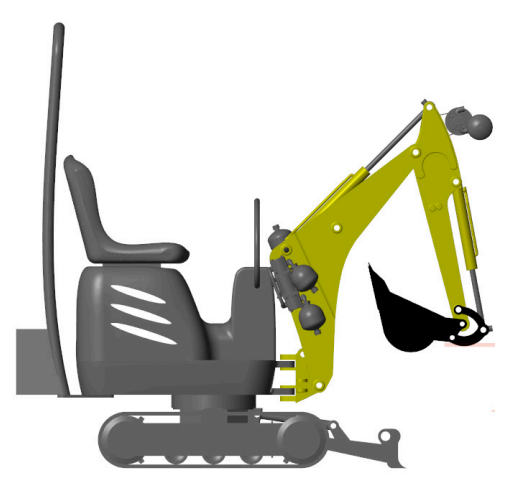

(a)

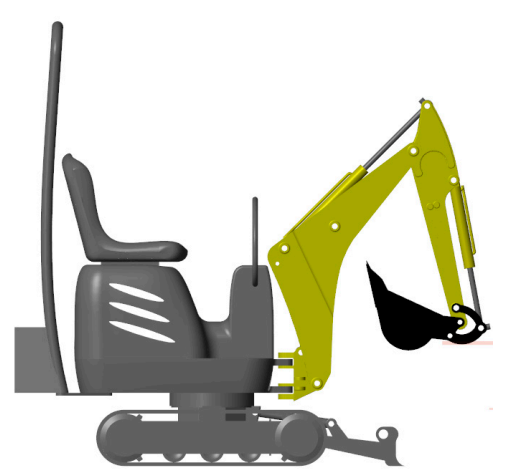

(b)

Figure 15. Mechanical model of the excavator (a) with DDH units; (b) without DDH units.

As components of $\mathrm{DDH}$, the cylinder, pump/motor, accumulator, and pipe are realized in the MATLAB/Simulink environment. Most of their detailed explanations refer to work in [28]. In addition, further improvements to the model were performed. Switching between motoring and pumping mode was added. This improved pump modelling significantly. The leakage models of pumps-external bi-directional gear motors by Hydac - were updated with the analytical method [29]. The hose model was updated with a pressure drop. The overall model is considered to be reliable, as it was validated in early studies in [16]; and in addition, the cylinder friction was validated with a micro-excavator [30].

Following section introduces utilized analytical model the pump/motor. The overall leakage flow rate and friction torque depend on the pressure differential over the pump/motor.

The leakage flow rate is given in Equation (1):

$$
q_{\text {Leak }}=K_{\mathrm{HP}} \Delta p
$$


and the friction torque is as shown in Equation (2):

$$
\tau_{\mathrm{r}}=\tau_{0}+K_{\mathrm{TP}}|\Delta p| \tanh \left(\frac{4 \omega}{\omega_{\text {Thresh }}}\right),
$$

where $K_{\mathrm{HP}}$ is the Hagen-Poiseuille coefficient for laminar pipe flows, and $K_{\mathrm{TP}}$ is the friction torque vs the pressure gain coefficient, $\tau_{0}$ is the no-load torque, and $\omega_{\text {Thresh }}$ is the threshold angular velocity for the pump-motor transition.

The Hagen-Poiseuille and the friction torque coefficients are determined from nominal fluid and component parameters through the Equations (3) and (4):

$$
\begin{gathered}
K_{\mathrm{HP}}=\frac{v_{\mathrm{Nom}}}{\rho v} \frac{\rho_{\mathrm{Nom}} \omega_{\text {Nom }} V}{\Delta p_{\mathrm{Nom}}}\left(1-\eta_{\mathrm{V}, \mathrm{Nom}}\right), \\
K_{\mathrm{TP}}=\frac{V}{2 \pi \cdot 10^{6}}\left(\frac{\eta_{\mathrm{V}, \mathrm{Nom}}}{\eta_{\text {Total }}}-1\right),
\end{gathered}
$$

where $v_{\text {Nom }}$ and $\rho_{\text {Nom }}$ are the nominal kinematic viscosity and fluid density of the fluid. $\omega_{\text {Nom }}$ and $\Delta p_{\text {Nom }}$ are the nominal shaft angular velocity and the pressure difference of the pump/motor, respectively. $\eta_{\mathrm{v}, \mathrm{Nom}}$ is the volumetric efficiency at nominal conditions. $v$ and $\rho$ are the actual density and kinematic viscosity of the fluid. The volumetric efficiencies $\eta_{\mathrm{v}, \mathrm{Nom}}$ and the hydro-mechanical efficiencies of the selected motors are extracted and calculated based on the curves in the datasheet by Hydac, which contain the flow and torque varying with speed at nominal pressure. Table 5 illustrates

\begin{tabular}{|c|c|c|c|c|}
\hline Parameter & MGE102-630 & MGE102-450 & MGE101-630 & MGE101-400 \\
\hline Displacement $\left(\mathrm{cm}^{3} / \mathrm{rev}\right)$ & 6.61 & 4.95 & 6.67 & 4.27 \\
\hline Rotational speed (rpm) & \multicolumn{4}{|c|}{1450} \\
\hline Oil kinematic viscosity at $40^{\circ} \mathrm{C}\left(\mathrm{mm}^{2} / \mathrm{s}\right)$ & \multicolumn{4}{|c|}{36} \\
\hline Oil density at $40^{\circ} \mathrm{C}\left(\mathrm{kg} / \mathrm{m}^{3}\right)$ & \multicolumn{4}{|c|}{860} \\
\hline Nominal pressure (bar) & 250 & 250 & 230 & 250 \\
\hline Volumetric efficiency (\%) & 93.1 & 91.5 & 95.4 & 94.0 \\
\hline Hydromechanical efficiency (\%) & 88.2 & 83.3 & 85.4 & 83.3 \\
\hline No-load torque $(\mathrm{Nm})$ & \multicolumn{4}{|c|}{0.05} \\
\hline
\end{tabular}
parameters of the pump/motor provided by manufacturer (Hydac).

Table 5. Parameters of the pump/motors provided by Hydac.

In order to look into the energy efficiency effect of the extra weight produced by DDH units on the front attachment of the excavator, the simulation adopting different cycles are done with and without this extra weight of DDH units. The following subsection introduces the results of the simulation study and their analyses.

\subsection{Results}

The power of cylinder is calculated by the product of the hydraulic force and the velocity of the cylinder, including the friction effect, as given in Equation (5):

$$
P_{\text {cylinder }}=\left(p_{\mathrm{A}} A_{\mathrm{A}}-p_{\mathrm{B}} A_{\mathrm{B}}\right) \dot{x},
$$

where the $p_{\mathrm{A}}$ and $p_{\mathrm{B}}$ are the pressures in the piston (A) and rod (B) chambers of the cylinder; $A_{\mathrm{A}}$ and $A_{\mathrm{B}}$ are the effective areas in the $\mathrm{A}$ and $\mathrm{B}$ chambers of the cylinder; and $x$ is the displacement of the piston. 
Pump A or pump B is running in pumping mode when the product of the pressure difference over the pump and its angular velocity is positive, and running in motoring mode when this product is negative, as shown in Equation (6):

$$
P_{\text {pump }}=\left\{\begin{array}{cl}
\Delta p_{\text {pump }} V_{\text {pump }} \omega / \eta_{\text {hm,pump }} & \left(\Delta p_{\text {pump }} \omega>0, \text { in pumping mode }\right) \\
\Delta p_{\text {pump }} V_{\text {pump }} \omega \eta_{\text {hm,pump }} & \left(\Delta p_{\text {pump }} \omega<0, \text { in motoring mode }\right)
\end{array},\right.
$$

where $P_{\text {pump }}, V_{\text {pump }}$, and $\eta_{\mathrm{hm} \text {,pump }}$ are the power, the displacement, and the hydromechanical efficiency of the pump, respectively.

The power of the electrical motor was computed by using the sum power of pump A and pump B divided by its efficiency, as given in Equation (7):

$$
P_{\mathrm{e}-\text { motor }}=\left(P_{\text {Apump }}+P_{\text {Bpump }}\right) / \eta_{\mathrm{e}-\text { motor }}
$$

where $P_{\text {Apump }}$ and $P_{\text {Bpump }}$ are the powers of pumps A and B in a DDH unit, $\omega$ is the angular velocity of the shaft connecting pumps and the electric motor, and $P_{\mathrm{e}-\text { motor }}$ and $\eta_{\mathrm{e} \text {-motor }}$ are the power and efficiency of the electric motor.

Figures 16 and 17 illustrate the power distribution of each cylinder and for the typical digging cycle with and without the extra weight of DDH units. Comparing Figures 16 and 17 reveals a slight variation in power requirements for systems with and without the extra weight of DDH units. During the boom up in the typical digging cycle, the mean powers demanded by the electric motor of boom DDH are $1.6 \mathrm{~kW}$ and $1.1 \mathrm{~kW}$ for considering and ignoring the weight of the DDH units. Additionally, the peak power of the boom electric motor during the boom up are $3.0 \mathrm{~kW}$ and $2.4 \mathrm{~kW}$, respectively. The power distribution of bucket DDH does not change due to no DDH being installed on the bucket.
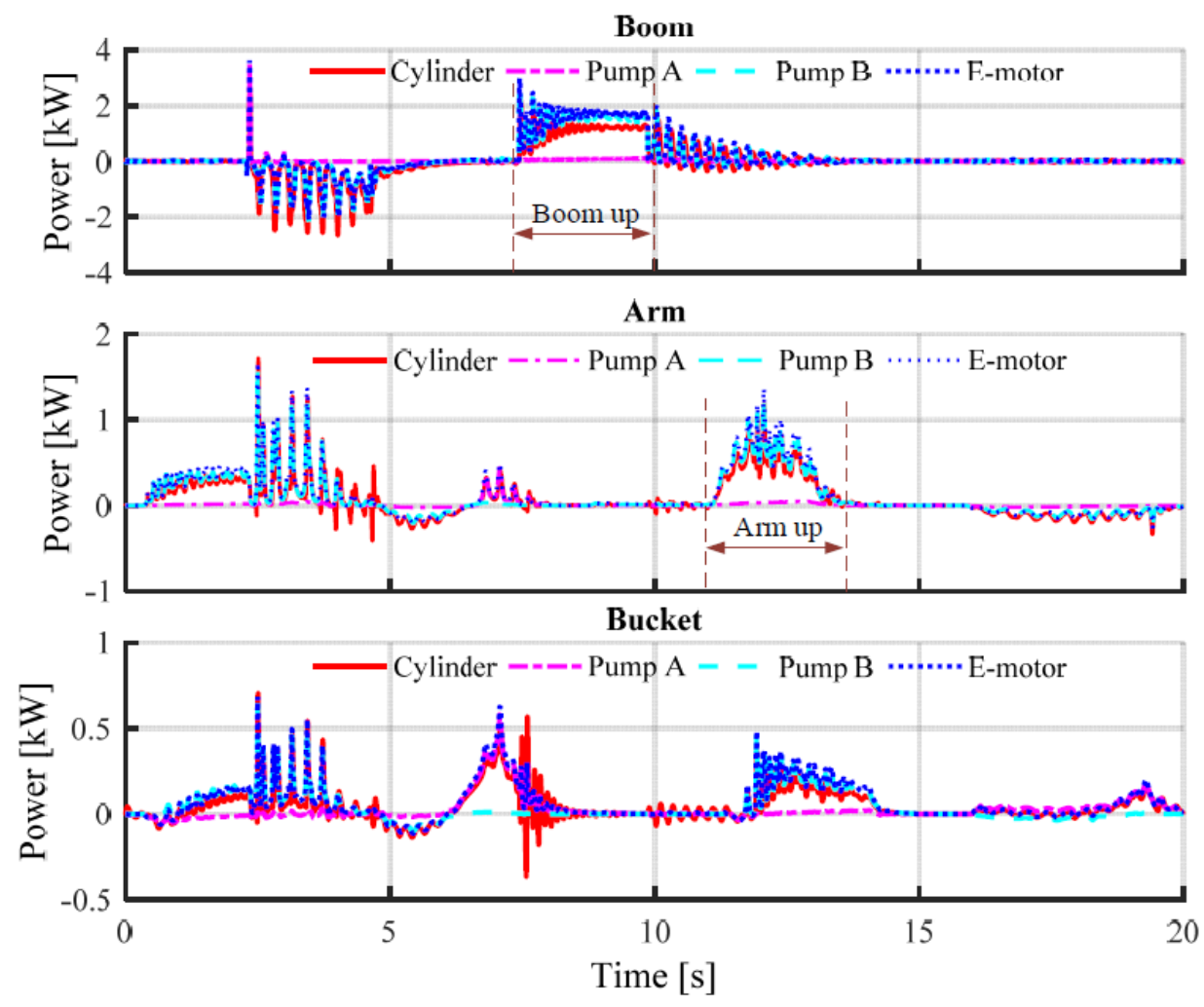

Figure 16. Power distribution of each cylinder in typical digging cycle with DDH unit weight. 


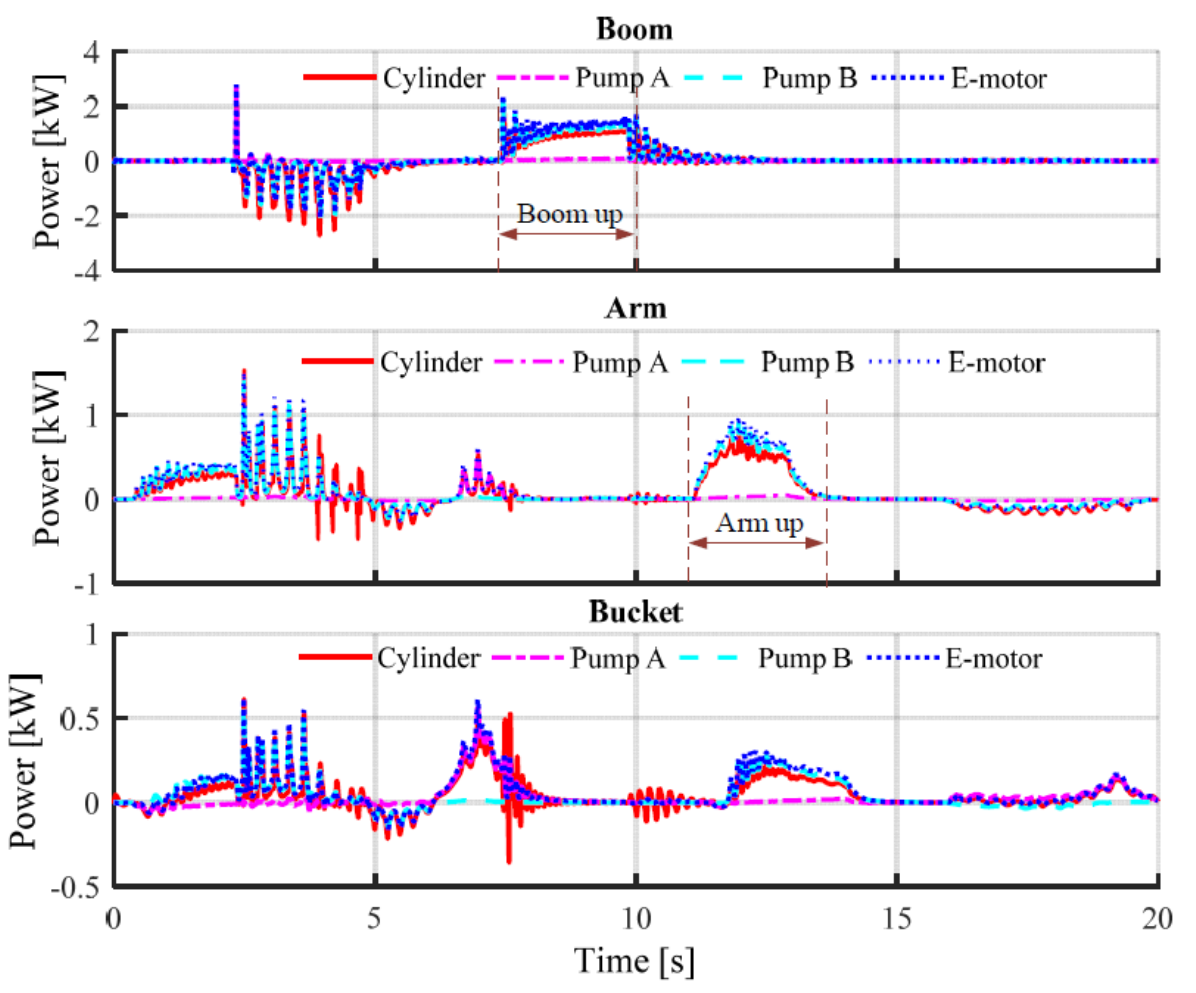

Figure 17. Power distribution of each cylinder in typical digging cycle without DDH unit weight.

Figure 18 presents the overall power distributions of cylinders, pumps, electric motors, and regeneration in the typical digging cycle. When the power of the cylinders is positive, it means the system is consuming electric power.

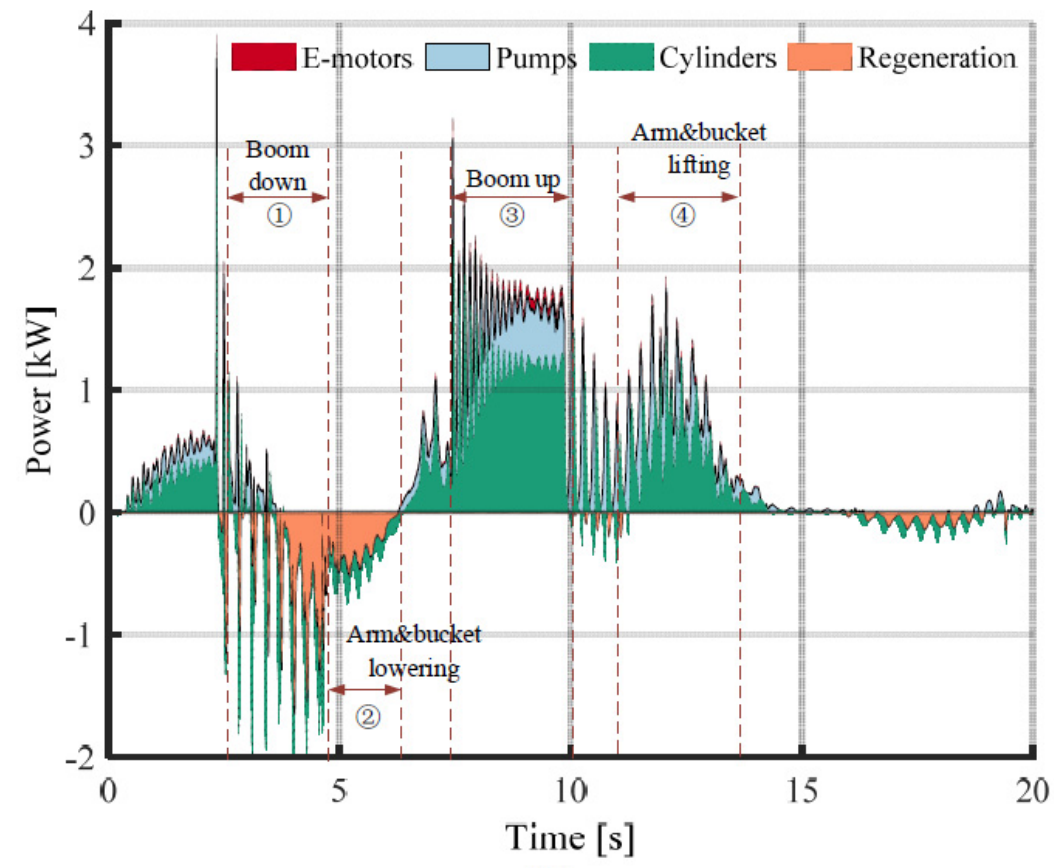

(a)

Figure 18. Cont. 


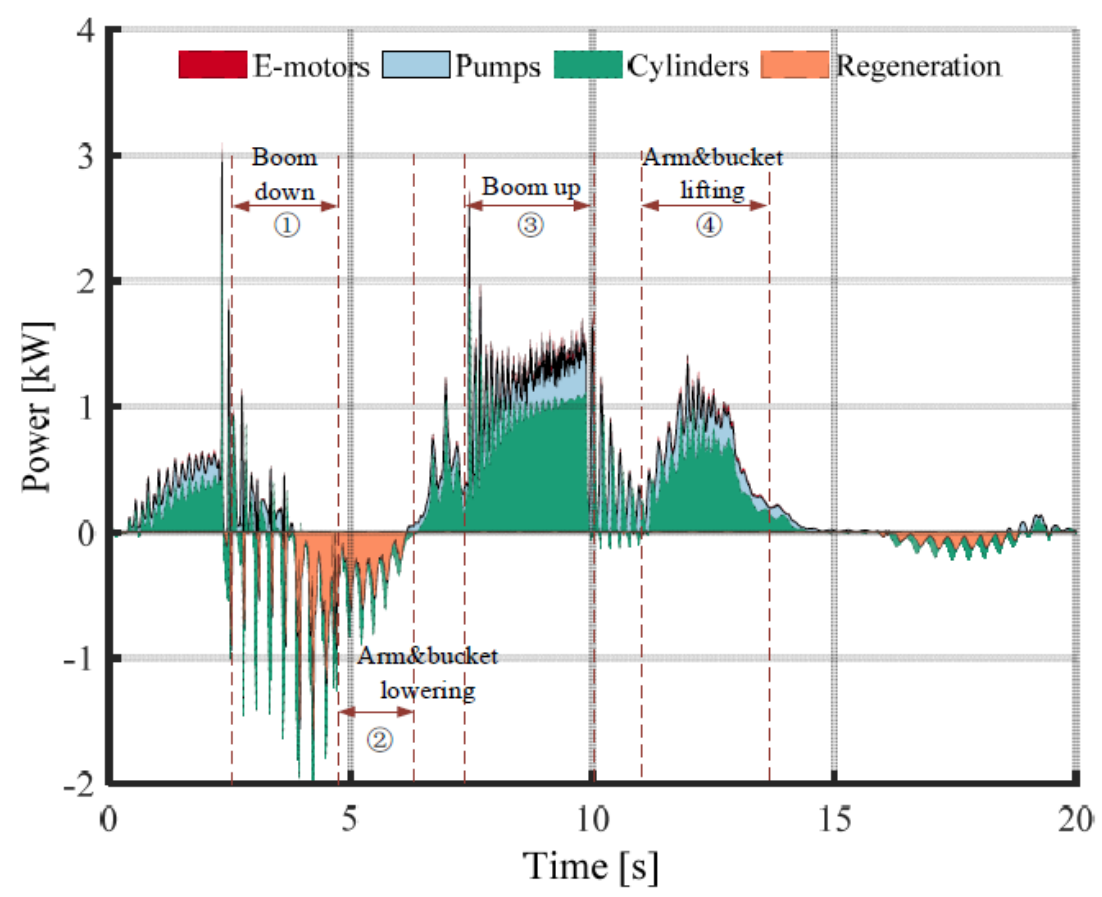

(b)

Figure 18. The overall power distribution of each component in a typical digging cycle (a) with DDH unit weight; (b) without DDH unit weight.

In contrast, the system converts the potential and kinetic energy into electric power. The extra weight of DDH units mainly affects the consuming and the regenerating power of the boom and arm DDH units, but not the bucket. Phases 1 and 2 in Figure 18a,b demonstrate the possibility of energy regeneration and the regeneration power slightly increasing during boom down and arm \& bucket lowering. During the boom up and arm \& bucket lifting, phases 3 and 4 show that the more power demanded by the system grows due to the extra weight of the DDH units.

The overall regeneration energy $E_{\mathrm{Reg}}$ and energy consumption $E_{\mathrm{DDHs}}$ of DDH units are computed by integrating the negative and positive part of the power of the electric motors, as shown in Equations (8) and (9):

$$
\begin{aligned}
& E_{\text {Reg }}=-\int_{t_{1}}^{t_{2}} P_{\mathrm{e}-\text { motors }} d t\left(P_{\mathrm{e}-\text { motors }}<0\right), \\
& E_{\mathrm{DDHs}}=\int_{t_{1}}^{t_{2}} P_{\mathrm{e}-\text { motors }} d t\left(P_{\mathrm{e}-\text { motors }}>0\right),
\end{aligned}
$$

where $P_{\text {cylinders }}$ and $P_{\mathrm{e}-\text { motors }}$ are the powers of the three cylinders and three electric motors, and $t_{1}$ and $t_{2}$ are the start and end time of the working cycle.

Without considering the regeneration possibility of the DDH units, the overall energy efficiency $\eta_{\mathrm{DDHs}}$ is calculated with the integration of the positive power of a cylinder (including the friction effect) divided by the integration of the positive power into electric motors, as shown in Equation (10). In addition, the regeneration efficiency of DDH units is computed with the integration of the negative power of the electric motors divided by the integration of the negative power of the cylinders, as shown in Equation (11):

$$
\eta_{\mathrm{DDHs}}=\frac{\int_{t_{1}}^{t_{2}} P_{\text {cylinders }} d t}{\int_{t_{1}}^{t_{2}} P_{\mathrm{e}-\text { motors }} d t}=\frac{\int_{t_{1}}^{t_{2}} P_{\text {cylinders }} d t}{E_{\mathrm{DDHs}}}\left(P_{\text {cylinders }}>0, P_{\mathrm{e}-\text { motors }}>0\right),
$$




$$
\eta_{\text {Reg }}=\frac{\int_{t_{1}}^{t_{2}} P_{\mathrm{e}-\text { motors }} d t}{\int_{t_{1}}^{t_{2}} P_{\text {cylinders }} d t}=\frac{-E_{\mathrm{Reg}}}{\int_{t_{1}}^{t_{2}} P_{\text {cylinders }} d t}\left(P_{\text {cylinders }}<0, P_{\mathrm{e}-\text { motors }}<0\right)
$$

Table 6 illustrates the energy consumption and efficiency analysis results, including three varying cycles: typical digging cycles, modified Japanese digging cycle, and levelling cycle.

Table 6. Energy consumption and efficiency analysis.

\begin{tabular}{cccc}
\hline \multirow{2}{*}{ Cycle } & Parameter & \multicolumn{2}{c}{ Weight of 3 DDH Units } \\
\cline { 3 - 4 } & & Without & With \\
\hline & Energy consumption (kJ) & 8.1 & 9.4 \\
Typical working cycle & Overall efficiency (\%) & 71.1 & 69.4 \\
(payload 71.9 kg) & Regeneration energy (kJ) & 1.9 & 2.3 \\
& Regeneration efficiency (\%) & 69.6 & 68.1 \\
\hline \multirow{3}{*}{ Modified digging Japanese } & Energy consumption (kJ) & 4.9 & 5.8 \\
cycle (payload 0 kg) & Overall efficiency (\%) & 68.0 & 69.6 \\
& Regeneration energy (kJ) & 1.5 & 1.8 \\
& Regeneration efficiency (\%) & 75.0 & 71.0 \\
\hline \multirow{2}{*}{ Modified levering Japanese } & Energy consumption (kJ) & 3.5 & 3.9 \\
cycle (payload 0 kg) & Overall efficiency (\%) & 68.7 & 69.5 \\
& Regeneration energy (kJ) & 1.1 & 1.4 \\
& Regeneration efficiency (\%) & 71.0 & 69.7 \\
\hline
\end{tabular}

The results show that the energy consumption is approximately $15 \%(15.4 \%, 18.9 \%$, and $13.5 \%)$ higher, with extra weight produced by the three DDH units for the typical digging cycle, JCMAS digging and leveling cycle. Although approximately $20 \%(26.3 \%, 22.6 \%$, and $18.2 \%)$ more regeneration energy is produced, taking into account the regeneration energy, the increases in energy consumption are $12.2 \%, 17.2 \%$, and $11.1 \%$. For the selected working cycle, the energy consumption with the added weight of DDH units is higher, and the same time regenerative energy is also higher compared to the system without added weight.

\section{Discussion and Future Outlook}

In this study, Direct Driven Hydraulics (DDH) is described as a response to the ongoing trend for electrification of NRMMs. In order to demonstrate the benefits of the zonal hydraulics approach implemented with DDH for the excavator study case, this paper proposed a system model approach to assess and predict energy consumption in various working cycles, complemented by a structural analysis.

\subsection{Structural Analysis}

The finite element analysis was utilized to demonstrate that the extra weight and selected location of DDH units do not negatively affect the structure of the excavator. The prepared 3D model in CREO 3.0 to simulate loading conditions of micro-excavator has its limitations. For instance, the internal dimensions of the boom and arm were inaccessible for measuring without destroying the part itself. Therefore, some of the internal features, such as wall thickness, were modelled by comparing them to other excavator parts that were accessible for measurements. The weld seams and detail features around corners are neglected in the model. This simplification can have a significant impact on local stresses around those locations. The peak stress observed in FEA of the boom was close to an edge near the boom-boom cylinder joint, while almost everywhere else the stress levels were far below the peak value, as can be seen from Figure 7 .

This paper has only studied the static structural response of the boom with the addition of DDH units. In practical application, dynamic loading such as vibrations and friction due to the rotation of 
the electric motor and hydraulic pumps can result in a different mode of global vibration on the boom and front hoe as a whole. These behaviours should be studied further to assure that the destructive phenomena such as resonance resulting in high stresses and deformations would not occur during use of DDH units attached on the front hoe of micro-excavator.

The additional loading during bucket-soil interaction can produce impact-loading, the effect of which can be studied further to check the robustness of DDH units and relocate or redesign them, making units suitable for practical use. The numerical values of stress obtained from FEA were irrelevant if not compared to something else. The design stress limits of the boom are unknown, and an estimation of the stress limit using dimensions, load, and the material properties can still give unreliable values. In order to get rid of such a dilemma, the stresses of the boom with and without DDH units are compared using the exact same load and boundary conditions. If there were errors in stress values due to defects in the model, it would be the same for both cases with and without DDH units, hence the difference in stress states would still be reliable.

It is challenging to consider the location of zonal hydraulics, as non-symmetrical locations of $\mathrm{DDH}$ units may cause problems such as collision, blocking view of an operator, limiting workspace and causing mechanical vibrations. In an ideal case, the cylinders of the front hoe could be modified to accommodate most of the DDH parts within itself. However, it was not feasible for the current research due to limited time and resources.

\subsection{Energy Consumption Analysis}

Although DDH units increase stress and increase weight, DDH brings potential energy regeneration, which is not normally available in conventional valve-controlled systems. The MATLAB/ Simulink modelling results demonstrated that the energy consumption is approximately $15 \%$ higher with the extra weight added by the three DDH units compared to the excavator, without taking into account the weight of the DDH units. In addition, more regenerative energy can be obtained in the standard test cycle in the excavator with the added three DDH units. Despite simplifications regarding losses and cycles in the model, significant differences in total energy efficiency were captured between the components. However, for future development, these simplifications should be taken into account. Also, cavitation problems were not investigated in this study, but it should be included in future research. The load model was simplified, as the actual digging cycle does not have penetration into the pile. This was excluded due to the complexity of the terra-mechanical forces. Data acquisition is not currently available for quantifying these forces. The effect of various working cycles with a payload and extreme operation points (such as speed and pressure) should be investigated in the future.

Nowadays, electrification and hybridization are considered to be relevant options to replace conventional valve-controlled systems in order to improve overall efficiency and reduce energy consumption. Despite the demonstrated high efficiency of DDH and the extended range of electric drive that can be obtained due to regenerative energy, it is important to notice that it is coming with the price of extra electric components, such as an expensive battery, electric motors, and motor controllers. The requirement of a high initial investment usually scares the manufacturer and their customers. However, return of investment time due to achieved advantages should be calculated, and the price increase for a new vehicle should be estimated in future work.

Furthermore, to prove the applicability of the proposed electrification by means of zonal hydraulics, these results should be validated against measurements and utilized for the development of a proof of concept for the application of zonal hydraulics for the micro-excavator and other off-road machinery.

The efficiency behaviour of DDH components and the overall efficiency of the triple DDH system were determined. Partial validation of the model showed acceptable results. The detail level of the model could be improved based on validation results. The efficiency estimation was based on a simulation combining data from manufacturers and experimentation. Productivity and efficiency 
analyses should be performed for the proposed zonal approach to investigate the benefits of this system in more detail.

Control for DDH units was not the focus of this research. A self-adjusting fuzzy PID control was implemented as a speed control for the electric motor, using a fixed PID control as the current control (electric motor vector control $i_{\mathrm{d}}=0$ ) and cylinder position control as a response to load-torque disturbance. Therefore, evaluation of the control strategy of the DDH and its effect on the dynamic performance of the hydraulic system should be performed in the near future.

In this simulation study, the drive for the DDH was directly powered from the electrical grid, and the energy storage, converter, and power electronics were not considered in this stage of the research. Consequently, the regenerated potential energy was not stored. However, energy storage could be accomplished using a battery or super capacitor, despite the disadvantages of the expenses for additional components. Energy storage and its management system, power electronics, and three frequency converters will affect price, efficiency, and maintenance of the zonal hydraulics. Therefore, further investigation of these electric components will be included in the near future as part of the modelling study.

\section{Conclusions}

This paper investigated the effect of extra weight caused by the Direct Driven Hydraulics $(\mathrm{DDH})$ in a micro-excavator to the structure of the boom and to energy consumption. The energy consumption of the zonal hydraulics approach implemented with DDH units was investigated for various working cycles. This investigation was based on a MATLAB/Simulink model coupled with multibody dynamics and structural analysis based finite element method. The modelling results demonstrated that the energy consumption is approximately $15 \%(15.4 \%, 18.9 \%$, and $13.5 \%)$ higher with the extra weight produced by the three DDH units for a typical digging cycle, JCMAS digging and levelling cycle. Although more than approximately $20 \%(26.3 \%, 22.6 \%$, and $18.2 \%)$ regeneration energy is produced-taking into account the regeneration energy-the increases in energy consumption are $12.2 \%, 17.2 \%$, and $11.1 \%$. In addition, more regenerative energy was captured in the standard test cycle. The structural analysis demonstrated that the extra weight and selected location of DDH units do not negatively affect the structure of the excavator despite the increase in stresses and deflections. Therefore, the proposed modification can be considered to be safe, and it allows attachment of the DDH units for finalizing research and construction of the full prototype of the excavator with zonal hydraulics.

Author Contributions: A.N. performed the mechanical analysis; S.Z. analysed the simulation data; and A.N., S.Z., and T.M. wrote the paper. M.P. contributed to the discussion of the results.

Funding: The research was enabled by the financial support of Tekes (the Finnish Funding Agency for Innovation, project EL-Zon) and the Academy of Finland (IZIF project), and internal funding at the Department of Mechanical Engineering at Aalto University. Additionally, research was supported by the Natural Science Foundation of Fujian Province (No. 2016J01203), the Scientific Research Fund (No. GY-Z15096), and the Public Service Platform for Technical Innovation of Machine Tool Industry at Fujian University of Technology.

Conflicts of Interest: The authors declare no conflict of interest. The founding sponsors had no role in the design of the study, in the collection, analyses, and interpretation of the data, in the writing of the manuscript, and in the decision to publish the results.

\section{References}

1. A Roadmap for Heavy-Duty Engine $\mathrm{CO}_{2}$ Standards within the European Union Framework. September 2017. Available online: https://www.theicct.org/sites/default/files/publications/EU-HDV-CO2-enginestds_ICCT-Briefing_04092017_vF.pdf (accessed on 5 January 2018).

2. DieselNet. United States: Nonroad Diesel Engines, Tier 4 Emission Standards. Available online: https: / / www.dieselnet.com/standards/us/nonroad.php\#tier4 (accessed on 8 March 2018).

3. Casoli, P.; Riccò, L.; Campanini, F.; Bedotti, A. Hydraulic Hybrid Excavator-Mathematical Model Validation and Energy Analysis. Energies 2016, 9, 1002. [CrossRef] 
4. Lin, T.; Huang, W.; Ren, H.; Fu, S.; Liu, Q. New compound energy regeneration system and control strategy for hybrid hydraulic excavators. Autom. Constr. 2016, 68, 11-20. [CrossRef]

5. Hassi, T.; Korva, A.; Markkula, S.; Partanen, T.; Sourander, T.; Kiviluoma, P.; Korhonen, A.; Kuosmanen, P. Improving Energy Efficiency of an Electric Mini Excavator. In Proceedings of the International DAAAM Baltic Industrial Engineering Conference, Tallinn, Estonia, 20-22 April 2016.

6. Edamura, M.; Ishida, E.S.; Imura, S.; Izumi, S. Adoption of Electrification and Hybrid Drive for More Energy-Efficient Construction Machinery. Hitachi Rev. 2013, 62, 118-122.

7. Hippalgaonkar, R.; Ivantysynova, M. A Series-Parallel Hydraulic Hybrid Mini-Excavator with Displacement Controlled Actuators. In Proceedings of the 13th Scandinavian International Conference on Fluid Power, Linköping, Sweden, 3-5 June 2013; pp. 31-42.

8. Gawlik, A.; Sobczyk, A.; Walczak, P. Hydraulic hybrid vehicle with energy recuperation. Mech. Zesz. 2016. [CrossRef]

9. Breen, J. JCB's First 'Electric' Excavator Breaks Ground. Available online: https://www.agriland.ie/farmingnews/jcbs-first-electric-excavator-breaks-ground/ (accessed on 30 July 2018).

10. KATO Works. 17VXE Electric Mini Excavator. Available online: http://ihicompactexcavator.com/product/ 17vxe-electric-mini-excavator/ (accessed on 30 July 2018).

11. Sennebogen. Electric Excavator. 2018. Available online: https://www.sennebogen.com/en/products/ electric-excavator.html (accessed on 30 June 2018).

12. Volvo. Volvo Ce Unveils 100\% Electric Compact Excavator Prototype. 2017. Available online: https:/ / www.volvoce.com/global/en/news-and-events/news-and-press-releases/volvo-ce-unveils-100percent-electric-compact-excavator-prototype/ (accessed on 30 June 2018).

13. Lodewyks, J.; Zurbrügg, P. Decentralized Energy-Saving Hydraulic Concepts for Mobile Working Machines. In Proceedings of the 10th International Fluid Power Conference, Dresden, Germany, 8-10 March 2016.

14. Weber, J.; Beck, B.; Fischer, E.; Ivantysyn, R.; Kolks, G.; Kunkis, M.; Lohse, H.; Lübbert, J.; Michel, S.; Schneider, M.; et al. Novel System Architectures by Individual Drives. In Proceedings of the 10th International Fluid Power Conference, Dresden, Germany, 8-10 March 2016.

15. Hänninen, H.; Minav, T.; Pietola, M. Replacing a constant pressure valve controlled system with a pump controlled system. In Proceedings of the 2016 Bath/ASME Symposium on Fluid Power and Motion Control, FPMC2016, Bath, UK, 7-9 September 2016.

16. Zhang, S.; Minav, T.; Pietola, M. Decentralized Hydraulics for Micro-excavator. In Proceedings of the 15th Scandinavian International Conference on Fluid Power, SICFP'17, Linköping, Sweden, 7-9 June 2017.

17. Minav, T.A.; Heikkinen, J.E.; Pietola, M. Direct Driven Hydraulic Drive for New Powertrain Topologies of Non-Road Mobile Machines, Elsevier, Electric Power System Research, ISSN 0378-7796. Electr. Power Syst. Res. 2017, 152, 390-400. [CrossRef]

18. HYDAC Internaltional. Motor Specifications. 2016. Available online: https://www.hydac.com/fileadmin/ pdb/pdf/PRO0000000000000000000029021000011.pdf (accessed on 26 November 2017).

19. Rexroth Bosch Group. Rexroth IndraDyn T Synchronous Torque Motors. Available online: https:// www.boschrexroth.com/country_units/america/united_states/sub_websites/brus_dcc/documentation_ downloads /ProductDocumentation/CurrentProducts/Motors/IndraDyn_T/29879803.pdfpdf (accessed on 26 November 2017).

20. Mieth, S.; Voigt, S.; Kunze, G. Typical performance cycles of mobile machinery taking into account the operator influence. In Proceedings of the 8th International Fluid Power Conference, Dresden, Germany, 26-28 March 2012.

21. Zimmerman, J.D.; Pelosi, M.; Williamson, C.A.; Ivantysynova, M. Energy consumption of an LS excavator hydraulic system. In Proceedings of the ASME 2007 International Mechanical Engineering Congress and Exposition, Seattle, WA, USA, 11-15 November 2007; pp. 117-126.

22. Japan Construction Mechanization Association. JCMAS H. 020:2007. Earth-Moving Machinery—Fuel Consumption on Hydraulic Excavator-Test Procedures [S]; Excavators AFH; Construction JCMA: Tokyo, Japan, 2007.

23. Salomaa, V.; Minav, T.; Mattila, J.; Pietola, M. Energy loss analysis of an electro-hydraulic excavator. In Proceedings of the 11th International Fluid Power Conference, Aachen, Germany, 19-21 March 2018.

24. Volumetric Rating of Excavator Mounted, Bucket Linkage Operated Grapples. Available online: http: / / standards.sae.org/j2754_201405/pdf (accessed on 20 August 2017). 
25. BS 6422: 1983, ISO 7546-1983-Method for Volumetric Rating of Loader and Front Loading Excavator Buckets Used for Earth-moving; CECE 2:1 Standard B/513/1. 1983. Available online: https://www.iso.org/ obp/ui/\#iso:std:iso:7546:ed-1:v1:en (accessed on 20 August 2017).

26. Ng, F.; Harding, J.A.; Glass, J. An eco-approach to optimise efficiency and productivity of a hydraulic excavator. J. Cleaner Prod. 2016, 112, 3966-3976. [CrossRef]

27. Goodluck, I.O.; Rodney, S.R.; Fernando, F. Bulking factor of rock for underground opening. Available online: https: / /www.nrc.gov/docs/ML0807/ML080700314.pdf (accessed on 20 August 2017).

28. Järf, A. Flow Compensation Using Hydraulic Accumulator in Direct Driven Hydraulic Differential Cylinder Application and Effects on Energy Efficiency. Master's Thesis, Aalto University, School of Engineering, Espoo, Finland, 2016.

29. The MathWorks Inc. Fixed-Displacement Pump. 2016. Available online: https://se.mathworks.com/help/ physmod/hydro/ref/fixeddisplacementpump.html (accessed on 5 February 2018).

30. Salomaa, V. Efficiency Study of an Electro-Hydraulic Excavator. Master's Thesis, Tampere University of technology, Espoo, Finland, 2017.

(C) 2018 by the authors. Licensee MDPI, Basel, Switzerland. This article is an open access article distributed under the terms and conditions of the Creative Commons Attribution (CC BY) license (http://creativecommons.org/licenses/by/4.0/). 